\title{
Exergetic Evaluation of Speed and Load Effects in Spark Ignition Engines
}

\author{
I. Sezer ${ }^{1}$ and A. Bilgin ${ }^{2}$ \\ 1 Mechanical Engineering Department, Gümüshane University, 29100 Gümüshane - Turkey \\ 2 Mechanical Engineering Department, Karadeniz Technical University, 61080 Trabzon - Turkey \\ e-mail: isezer@gumushane.edu.tr - bilgin@ktu.edu.tr
}

\begin{abstract}
Résumé - Évaluation exergétique des effets de la vitesse et de la charge dans les moteurs à allumage par étincelle - Cette étude examine les effets des différentes conditions de fonctionnement de moteurs à allumage commandé via une analyse exergétique. Un modèle de cycle thermodynamique comprenant les processus de compression, combustion et détente a été utilisé. Les processus d'admission et d'échappement sont modélisés à l'aide d'une méthode simple d'approximation. Les principes de la deuxième loi de la thermodynamique ont été appliqués au modèle de cycle pour effectuer l'analyse exergétique. Des variables exergétiques comme les transferts exergétiques de chaleur et de travail, les irréversibilités, l'exergie thermomécanique, l'exergie chimique du carburant et l'exergie totale ont été calculées dans l'analyse exergétique. La variation des paramètres exergétiques et leur distribution dans l'exergie du combustible ont été déterminées pour différentes conditions de fonctionnement, c'est à dire différentes vitesses du moteur et différentes charges. L'efficacité déduite, d'une part, de la première et la deuxième loi de la thermodynamique et, d'autre part, de la consommation spécifique de carburant ont également été calculées pour révéler les conditions optimales de fonctionnement. Les résultats montrent que le transfert exergétique de chaleur diminue et que le transfert exergétique par l'échappement augmente avec la vitesse du moteur. Le régime moteur de $3000 \mathrm{tr} / \mathrm{min}$ donne le transfert d'exergie maximal de travail, les irréversibilités minimales, les meilleurs rendements et la moindre consommation de carburant. Les transferts exergétiques avec la chaleur, le travail et l'échappement et ainsi que les irréversibilités augmentent avec la charge du moteur. En outre, l'efficacité déduite de la première et la seconde loi de la thermodynamique augmente et la consommation de carburant diminue avec la charge du moteur, donc une charge du moteur élevée donne les meilleurs rendements et la moindre consommation de carburant.
\end{abstract}

\begin{abstract}
Exergetic Evaluation of Speed and Load Effects in Spark Ignition Engines - This study investigates the effects of various operating conditions in spark ignition engines via an exergy analysis. A thermodynamic cycle model including compression, combustion and expansion processes was used for investigation. Induction and exhaust processes were computed with a simple approximation method. The principles of the second law were applied to the cycle model to perform the exergy analysis. Exergetic variables, i.e., the exergy transfers with heat and work, irreversibilities, thermomechanical exergy, fuel chemical exergy and total exergy were calculated in the exergy analysis. Variation of the exergetic parameters and the distribution of them into the fuel exergy were determined for various operating conditions, i.e., engine speed and load. The first and second law efficiencies and specific fuel consumption were also computed to reveal the optimum operating conditions. The results show that the exergy transfer with heat decreases and the exergy transfer with exhaust gases increases with increasing engine speed. Engine speed of $3000 \mathrm{rpm}$ gives the maximum exergy transfer as work, the minimum irreversibility and the best efficiency and fuel consumption. Exergy transfers with heat, work and exhaust and irreversibilities increase with increasing engine load. Additionally, the first and second law efficiencies increase and fuel consumption decreases with increasing engine load, so a high engine load gives the best efficiency and fuel consumption.
\end{abstract}




\section{NOMENCLATURE}

A Availability or exergy (J)

a Specific availability or exergy $(\mathrm{J} / \mathrm{kg})$

$b \quad$ Bore (m)

BMEP Brake Mean Effective Pressure (bar)

$B S F C$ Brake Specific Fuel Consumption (bar)

$c_{\mathrm{p}} \quad$ Specific heat at constant pressure $(\mathrm{J} / \mathrm{kg} \mathrm{K})$

E Energy (J)

$F \quad$ Surface $\left(\mathrm{m}^{2}\right)$

FMEP Friction Mean Effective Pressure (bar)

$h \quad$ Specific enthalpy $(\mathrm{J} / \mathrm{kg})$

I Irreversibility (J)

IMEP Indicated Mean Effective Pressure (bar)

$L \quad$ Length (m)

$m \quad$ Mass $(\mathrm{kg})$

$n \quad$ Engine speed (rpm)

$p \quad$ Pressure (bar)

$P \quad$ Power $(\mathrm{kW})$

$Q \quad$ Heat transfer (J)

$Q_{\mathrm{LHV}} \quad$ Lower heating value of fuel $(\mathrm{J} / \mathrm{kg})$

$r_{\mathrm{c}} \quad$ Compression ratio (dimensionless)

$S \quad$ Entropy $(\mathrm{J} / \mathrm{K})$

$s \quad$ Specific entropy $(\mathrm{J} / \mathrm{kg} \mathrm{K})$

$T \quad$ Absolute temperature (K)

$U \quad$ Internal energy ( $\mathrm{J})$

$u \quad$ Specific internal energy $(\mathrm{J} / \mathrm{kg})$

$V \quad$ Volume $\left(\mathrm{m}^{3}\right)$

$v \quad$ Specific volume $\left(\mathrm{m}^{3} / \mathrm{kg}\right)$

$W \quad$ Work $(\mathbf{J})$

$x_{\mathrm{b}} \quad$ Burned mass fraction (dimensionless)

$x_{\mathrm{r}} \quad$ Residual gas fraction (dimensionless)

$Z \quad$ Number of cylinder (dimensionless)

\section{Greek Letters}

$\Phi \quad$ Charge-up efficiency (\%)

$\varepsilon \quad$ Error (dimensionless)

$\phi \quad$ Fuel air equivalence ratio (dimensionless)

$\eta_{\mathrm{I}} \quad$ The first law efficiency (\%)

$\eta_{\text {II }} \quad$ The second law efficiency (\%)

$\eta_{\mathrm{vol}} \quad$ Volumetric efficiency (\%)

$\lambda \quad$ Heat transfer coefficient $\left(\mathrm{W} / \mathrm{m}^{2} \mathrm{~K}\right)$

$\mu \quad$ Chemical potential (J)

$\theta \quad$ Crank angle (CAD)

$\theta_{\text {st }} \quad$ Spark timing angle (CAD)

$\Delta \theta_{\mathrm{b}} \quad$ Burn duration (CAD)

$\sigma \quad$ Total entropy generation (J)

$\omega \quad$ Angular velocity $(\mathrm{rad} / \mathrm{s})$

\section{Subscripts}

0 Reference or dead-state conditions

b Burned

ch Chemical

clr Clearance

cr Connecting rod

comb Combustion

conv Convection

d Displacement

dest Destruction

e Effective (brake)

exh Exhaust

f Fuel

g Gas

IVC Intake valve closed

i Indicated

in Intake or inlet

kin Kinetic

max Maximum

pot Potential

Q Heat

r Residual

s Stroke

tm Thermomechanical

tot Total

toc Temperature of coolant

u Unburned

w Wall

W Work

\section{Superscripts}

- Derivation to the crank angle $(\mathrm{d} / \mathrm{d} \theta)$

\section{Abbreviation}

CAD Crank Angle Degree

MBT Maximum Brake Torque

ICE Internal Combustion Engine

\section{INTRODUCTION}

Extremely complex physical and chemical events occur during Internal Combustion Engine (ICE) operation. Variation of engine operating parameters such as the fuel-air equivalence ratio, spark timing, engine speed and engine load noticeably influence these events and also all performance parameters of an engine [1]. Engine cycle models are very suitable tools to investigate the effects of such parameters and also to evaluate the engine performance $[1,2]$. Cycle models of ICEs can be classified into two groups based on thermodynamics and 
fluid mechanics [2-5]. The thermodynamic cycle models were created in the 1960s and they are commonly used nowadays in both industry and academia due to the fact that they are economical and do not require high computer capacity or extensive operation time [6,7]. Additionally, only the first law of thermodynamics has been used in most of the work performed with the thermodynamic cycle models until now. However, the first law of thermodynamics is not adequate to study in detail the events relating to ICEs [7-10]. Therefore, the use of the second law of thermodynamics has intensified in the studies devoted to ICEs in recent times. Investigation of systems or processes by means of the second law of thermodynamics is called second law or exergy analysis. Exergy gives a quantitative and illustrative description of the convertibility of different energy forms. As is known, the processes in all real energy conversion systems are irreversible and a part of the exergy supplied to the total system is destroyed. The concept of exergy is extremely useful for the identification of the losses and irreversibility in the system by providing a more detailed tracking mechanism for the energy usage [9-12]. The real inefficiencies of a system are exergy destruction, occurring within the system boundaries and exergy losses, which are exergy transfers out of the system that are not further used in the overall system. For example, the exergy losses because of the friction, heat transfer and exhaust process and also irreversibilities sourced from the fluid motions, mixture formation, heat transfer and combustion phenomena can be determined by means of exergy analysis in ICEs, unlike an energy analysis. Thus, more efficient systems can be designed or performance of a present system can be improved by reducing the inefficiencies in the existing system. However, studies based on exergy analysis in the field of ICEs are limited compared with other ones. One of the previous studies devoted to exergy analysis of ICEs was performed by Traupel in 1957 [13]. Another previous study was completed by Patterson in 1962 [14]. Additionally, a series of studies on the application of exergy analysis to ICEs was carried out in the 1980s [15-19] and work on ICEs on the subject of exergy or the second law analysis has continued progressively in recent years [20-25]. In the present study, the effects of engine operating parameters such as engine speed and load are investigated via exergy analysis. To meet this goal, a thermodynamic cycle model originally developed by Ferguson [26] is adapted and used. The details of the cycle model and exergy analysis are given in the following section.

\section{MATHEMATICAL MODEL}

\subsection{Governing Equations of Cycle Model}

The governing equations of the cycle model are derived from the first law of thermodynamics (the energy equation) by assuming that cylinder content obeys the ideal gas law. The differential form of the first law is as follows for a closed system, i.e., engine cylinder [26, 27]:

$$
\dot{u} m+\dot{m} u=\dot{Q}-p \dot{V}
$$

Equation (1) shows that variation of the thermodynamic properties respects the crank angle. These thermodynamic properties are also functions of temperature and pressure. The following differential equations are used to determine cylinder pressure and burned and unburned gas temperatures through the simulation:

$$
\dot{p}=\frac{A+B+C}{D+E}
$$

here:

$$
A=\frac{\dot{V}}{m}
$$

$$
\begin{gathered}
B=\frac{\lambda_{\text {conv }}}{\omega m}\left[F_{\mathrm{b}}\left(1-\frac{T_{\mathrm{w}}}{T_{\mathrm{b}}}\right) \frac{v_{\mathrm{b}}}{c_{\mathrm{p}, \mathrm{b}}} \frac{\partial \ln v_{\mathrm{b}}}{\partial \ln T_{\mathrm{b}}}+F_{\mathrm{u}}\left(1-\frac{T_{\mathrm{w}}}{T_{\mathrm{u}}}\right) \frac{v_{\mathrm{u}}}{c_{\mathrm{p}, \mathrm{u}}} \frac{\partial \ln v_{\mathrm{u}}}{\partial \ln T_{\mathrm{u}}}\right] \\
C=-\left(v_{\mathrm{b}}-v_{\mathrm{u}}\right) \dot{x}_{\mathrm{b}}-v_{\mathrm{b}} \frac{h_{\mathrm{b}}-h_{\mathrm{u}}}{c_{\mathrm{p}, \mathrm{b}} T_{\mathrm{b}}} \dot{x}_{\mathrm{b}} \frac{\partial \ln v_{\mathrm{b}}}{\partial \ln T_{\mathrm{b}}} \\
D=x_{\mathrm{b}}\left[\frac{v_{\mathrm{b}}^{2}}{c_{\mathrm{p}, \mathrm{b}} T_{\mathrm{b}}}\left(\frac{\partial \ln v_{\mathrm{b}}}{\partial \ln T_{\mathrm{b}}}\right)^{2}+\frac{v_{\mathrm{b}}}{p} \frac{\partial \ln v_{\mathrm{b}}}{\partial \ln p}\right] \\
E=\left(1-x_{\mathrm{b}}\right)\left[\frac{v_{\mathrm{u}}^{2}}{c_{\mathrm{p}, \mathrm{u}} T_{\mathrm{u}}}\left(\frac{\partial \ln v_{\mathrm{u}}}{\partial \ln T_{\mathrm{u}}}\right)^{2}+\frac{v_{\mathrm{u}}}{p} \frac{\partial \ln v_{\mathrm{u}}}{\partial \ln p}\right]
\end{gathered}
$$

and:

$$
\begin{gathered}
\dot{T}_{\mathrm{b}}=\frac{-\lambda_{\text {conv }} F_{\mathrm{b}}\left(T_{\mathrm{b}}-T_{\mathrm{w}}\right)}{\omega m x_{\mathrm{b}} c_{\mathrm{p}, \mathrm{b}}}+\frac{v_{\mathrm{b}}}{c_{\mathrm{p}, \mathrm{b}}} \frac{\partial \ln v_{\mathrm{b}}}{\partial \ln T_{\mathrm{b}}} \dot{p}+\frac{h_{\mathrm{u}}-h_{\mathrm{b}}}{x_{\mathrm{b}} c_{\mathrm{p}, \mathrm{b}}} \dot{x}_{\mathrm{b}} \\
\dot{T}_{\mathrm{u}}=\frac{-\lambda_{\text {conv }} F_{\mathrm{u}}\left(T_{\mathrm{u}}-T_{\mathrm{w}}\right)}{\omega m\left(1-x_{\mathrm{b}}\right) c_{\mathrm{p}, \mathrm{u}}}+\frac{v_{\mathrm{u}}}{c_{\mathrm{p}, \mathrm{u}}} \frac{\partial \ln v_{\mathrm{u}}}{\partial \ln T_{\mathrm{u}}} \dot{p}
\end{gathered}
$$

The instantaneous volume of the cylinder is also determined as:

$$
V=V_{\text {clr }}\left\{1+\frac{r_{\mathrm{c}}-1}{2}\left[1-\cos \theta+\frac{1}{\chi} \alpha\right]\right\}
$$

In Equation (5):

$$
\begin{gathered}
\chi=L_{\mathrm{s}} / 2 L_{\mathrm{cr}} \\
\alpha=1-\left(1-\chi^{2} \sin ^{2} \theta\right)^{1 / 2}
\end{gathered}
$$

here, $L_{\mathrm{s}}$ and $L_{\mathrm{cr}}$ are stroke and connecting rod length, respectively. One can easily derive the $d V / d \theta$ from Equation (5).

The following differential equations are also used to determine indicated work and heat loss:

$$
\begin{gathered}
\dot{W}=p \dot{V} \\
\dot{Q}_{\mathrm{L}}=\frac{\lambda_{\text {conv }}}{\omega}\left[F_{\mathrm{b}}\left(T_{\mathrm{b}}-T_{\mathrm{w}}\right)+F_{\mathrm{u}}\left(T_{\mathrm{u}}-T_{\mathrm{w}}\right)\right]
\end{gathered}
$$


here, $\omega$ is the angular speed of the crankshaft that can be determined as:

$$
\omega=\frac{2 \pi n}{60}
$$

In the equations above, $\lambda_{\text {conv }}$, the convective heat transfer coefficient, is determined from the Woschni correlation as follows:

$$
\lambda_{\text {conv }}=3.26 b^{-0.2} p^{0.8} T^{-0.55} w^{0.8}
$$

In Equation (9), $w$ is average gas velocity, which is determined from:

$$
w=c_{1} \bar{S}_{p}+c_{2} \frac{V_{\mathrm{d}} T_{\mathrm{IVC}}}{p_{\mathrm{IVC}} V_{\mathrm{IVC}}}\left(p-p_{\mathrm{m}}\right)
$$

here, $\bar{S}_{p}$ and $p_{\mathrm{m}}$ are mean piston speed and motored pressure and $c_{1}$ and $c_{2}$ are constants. During compression $c_{1}=2.28$ and $c_{2}=0$; and during combustion and expansion $c_{1}=2.28$ and $c_{2}=3.24 \times 10^{-3}$ were used.

The cylinder wall temperature in the equations above is determined as follows [28]:

$$
T_{\mathrm{w}}=T_{\text {toc }}+R_{\mathrm{w}} \dot{Q}
$$

here, $T_{\text {toc }}$ and $R_{\mathrm{w}}$ are the temperature of the coolant and conductive resistance of the cylinder wall, respectively. $T_{\text {toc }}=350 \mathrm{~K}$ and $R_{\mathrm{w}} \cong 0.01 \mathrm{~K} / \mathrm{W}$ were used during simulation.

As is known, a Spark Ignition (SI) engine cycle consists of four consecutive processes: intake, compression, expansion (including combustion) and exhaust. In this study, the intake and exhaust processes are computed by using an approximation method [2]. In this method, the pressure and temperature of the intake process and volumetric efficiency are determined as follows:

$$
\begin{gathered}
p_{\text {in }}=p_{0}-\Delta p_{\text {in }} \\
T_{\text {in }}=\frac{T_{0}+\Delta T+x_{\mathrm{r}} T_{\mathrm{r}}}{1+x_{\mathrm{r}}} \\
\eta_{\mathrm{vol}}=\Phi \frac{r_{\mathrm{c}}}{r_{\mathrm{c}}-1} \frac{p_{\text {in }}}{p_{0}} \frac{T_{0}}{T_{\text {in }}\left(1+x_{\mathrm{r}}\right)}
\end{gathered}
$$

here, $\Delta p_{\text {in }}$ is pressure loss, which is determined from the Bernoulli equation for one-dimensional incompressible flow, $\Delta T$ is the increase in charge temperature throughout the intake system, $T_{\mathrm{r}}$ is the exhaust temperature in the previous cycle and $x_{\mathrm{r}}$ is the residual gas coefficient. $\Phi$ is also the charge-up efficiency which is determined from:

$$
\Phi=3.39 \times 10^{-5} n+0.9163
$$

Compression and expansion processes were computed from the governing equations of Equations (2-7) by the arrangement of them for each process in a suitable manner. The adiabatic flame temperature is assumed as the start of combustion temperature and the mass burning rate is computed from the cosine burn rate equation:

$$
x_{\mathrm{b}}=\frac{m_{\mathrm{b}}}{m_{\mathrm{tot}}}=\frac{1}{2}\left\{1-\cos \left(\frac{\pi\left(\theta-\theta_{\mathrm{st}}\right)}{\Delta \theta_{\mathrm{b}}}\right)\right\}
$$

In Equation (15), $\theta_{\mathrm{st}}$ is spark timing and $\Delta \theta_{\mathrm{b}}$ is burn duration, which is determined for certain operating parameters by using the following empirical correlations [29]:

$$
\begin{gathered}
f_{1}\left(r_{\mathrm{c}}\right)=3.2989-3.3612\left(r_{\mathrm{c}} / r_{\mathrm{c} 1}\right)+1.0800\left(r_{\mathrm{c}} / r_{\mathrm{c} 1}\right)^{2} \\
f_{2}(n)=0.1222+0.9717\left(n / n_{1}\right)-0.05051\left(n / n_{1}\right)^{2} \\
f_{3}(\phi)=4.3111-5.6383\left(\phi / \phi_{1}\right)+2.3040\left(\phi / \phi_{1}\right)^{2} \\
f_{4}\left(\theta_{\mathrm{st}}\right)=1.0685-0.2902\left(\theta_{\mathrm{st}} / \theta_{\mathrm{st} 1}\right)+0.2545\left(\theta_{\mathrm{st}} / \theta_{\mathrm{st} 1}\right)^{2} \\
\Delta \theta_{\mathrm{b}}\left(r_{\mathrm{c}}, n, \phi, \theta_{\mathrm{st}}\right)=f_{1}\left(r_{\mathrm{c}}\right) f_{2}(n) f_{3}(\phi) f_{4}\left(\theta_{\mathrm{st}}\right) \Delta \theta_{\mathrm{b} 1}
\end{gathered}
$$

here, $\Delta \theta_{\mathrm{b} 1}$ is the known combustion duration for the operating conditions of $r_{\mathrm{c} 1}, n_{1}, \phi_{1}$ and $\theta_{\mathrm{st} 1}$. The $\Delta \theta_{\mathrm{b} 1}$ is $24 \mathrm{CAD}$ when the baseline conditions are taken as $r_{\mathrm{c} 1}=7.5, n_{1}=1000 \mathrm{rpm}$, $\phi_{1}=1.0$, and $\theta_{\mathrm{st} 1}=-30 \mathrm{CAD}$. Thus, $\Delta \theta_{\mathrm{b}}$ is easily determined for the specified operating parameters.

The pressure and temperature for the exhaust process are also computed by using an approximation method [2]:

$$
\begin{gathered}
p_{\text {exh }}=c p_{0} \\
T_{\text {exh }}=\frac{T_{\mathrm{b}}}{\left(p_{\mathrm{b}} / p_{\text {exh }}\right)^{1 / 3}}
\end{gathered}
$$

here, $c$ is a constant between 1.05 and $1.25 ; p_{\mathrm{b}}$ and $T_{\mathrm{b}}$ is the final pressure and temperature of combustion. Further details of the cycle model can be found in references [26, 27].

\subsection{Engine Performance Parameters}

The engine performance parameters are determined from the widely known relations given below. Indicated and Brake Mean Effective Pressure are defined as follows:

$$
I M E P=\frac{W_{\mathrm{i}}}{V_{\mathrm{d}}}
$$

here, $W_{\mathrm{i}}$ is the indicated work output and $V_{\mathrm{d}}$ is displacement volume of a single cylinder:

$$
B M E P=I M E P-F M E P
$$

here, FMEP is the Friction Mean Effective Pressure, which is determined following a modified Barnes-Moss correlation for gasoline or SI engines:

$$
F M E P=0.6+\left(1.167 \times 10^{-4} n\right)+0.06 \bar{S}_{\mathrm{p}}
$$

The brake power is defined as:

$$
P_{\mathrm{e}}=\frac{B M E P V_{\mathrm{d}} n Z}{k 60}
$$

here, $k$ is a constant which is 1 for two-stroke engines and 2 for four-stroke engines. 
The first law (or energy-based) efficiency is defined as $[7,9,10]$ :

$$
\eta_{\mathrm{I}}=\frac{\text { Energy out }(\text { as work })}{\text { Energy in }}=\frac{W_{\mathrm{i}}}{m_{\mathrm{f}} Q_{\mathrm{LHV}}}
$$

here, $m_{\mathrm{f}}$ is the absolute mass of inducted fuel and $Q_{\mathrm{LHV}}$ is the lower heating value of the fuel.

Brake Specific Fuel Consumption is determined as:

$$
B S F C=\frac{3600 m_{\mathrm{f}}}{P_{\mathrm{e}}}
$$

\subsection{Governing Equations for Exergy Analysis}

The second law is analogous to the statement of entropy balance as follows $[7,9,10]$ :

$$
\Delta S=\int(Q / T)_{\text {boundary }}+\sigma
$$

here, $\sigma$ is the total entropy generation due to the internal irreversibilities.

Considering the combination of the first and second laws of thermodynamics the availability (or exergy) equation can be written for a closed system as $[7,9,10]$ :

$$
A=E+p_{0} V-T_{0} S
$$

here, $E$ is the total energy, which is a sum of the internal, kinetic and potential energies $\left(E_{\mathrm{tot}}=U+E_{\mathrm{kin}}+E_{\mathrm{pot}}\right)$.

Exergy is defined as the maximum theoretical work that can be obtained from a combined system (combination of a system and its reference environment) when the system comes into equilibrium (thermally, mechanically and chemically) with the environment. The maximum available work from a system emerges as the sum of two contributions: thermomechanical exergy, $A_{\mathrm{tm}}$, and chemical exergy, $A_{\mathrm{ch}}$. Thermomechanical exergy is defined as the maximum extractable work from the combined system, as the system comes into thermal and mechanical equilibrium with the environment, and it is determined as [7, 9-12]:

$$
A_{\mathrm{tm}}=E+p_{0} V-T_{0} S-\sum \mu_{0, i} m_{i}
$$

here, $m_{i}$ and $\mu_{0, i}$ are the mass and chemical potential of species $i$ calculated in restricted dead-state conditions.

In the restricted dead-state conditions, the system is in thermal and mechanical equilibrium with the environment and no work potential exists between the system and environment because of temperature and pressure differences. However, the system does not reach chemical equilibrium with the environment because the contents of the system are not permitted to mix with the environment or enter the chemical reaction by environmental components [30]. The difference between the compositions of the system in the restricted deadstate conditions and the environment can be used to obtain additional work, to reach chemical equilibrium. The maximum work obtained in this way is called the chemical exergy which can be determined from [7, 9-12, 30]:

$$
A_{\mathrm{ch}}=\sum m_{i}\left(\mu_{0, i}-\mu_{i}^{0}\right)
$$

here, $\mu_{i}^{0}$ is the chemical potential of species $i$ calculated in true dead-state conditions.

The exergy balance in any process for a closed system can also be written as [23]:

$$
\Delta A=A_{2}-A_{1}=A_{\mathrm{Q}}-A_{\mathrm{w}}-A_{\text {dest }}
$$

here, $\Delta A$ is the variation of the total system exergy, $A_{2}$ is the total exergy at the end of the process, $A_{1}$ is the total exergy at the start of the process, $A_{\mathrm{Q}}$ is the exergy transfer by heat interactions, $A_{\mathrm{W}}$ is the exergy transfer with work interactions, and $A_{\text {dest }}$ is the destroyed exergy through an irreversible process.

The exergy balance for an engine cylinder can also be written by considering the fuel chemical exergy [27, 31]:

$$
\dot{A}=\left(1-\frac{T_{0}}{T}\right) \dot{Q}-\left(\dot{W}-p_{0} \dot{V}\right)+m_{\mathrm{f}} a_{\mathrm{f}, \mathrm{ch}} \dot{x}_{\mathrm{b}}-\dot{I}_{\text {comb }}
$$

The left-hand side of Equation (31) refers to the rate of change in the total exergy in the cylinder. Thus, the total exergy of the cylinder content can be calculated from Equation (31) at any time and the exergy losses with exhaust gases can also be easily determined as the exergy remains in the cylinder at the end of the expansion period. The first and second terms on the right-hand side indicate exergy transfers with heat and work interactions. The third term on the right-hand side corresponds to the burned fuel exergy; here, $a_{\mathrm{f}, \mathrm{ch}}$ is the fuel chemical exergy. $a_{\mathrm{f}, \mathrm{ch}}$ is calculated by using the following equation for liquid fuels [32]:

$$
\begin{aligned}
& A_{\mathrm{f}, \mathrm{ch}}=m_{\mathrm{f}} a_{\mathrm{f}, \mathrm{ch}}=m_{\mathrm{f}} Q_{\mathrm{LHV}} \\
& {\left[1.0401+0.01728 \frac{h^{\prime}}{c^{\prime}}+0.0432 \frac{o^{\prime}}{c^{\prime}}+0.2196 \frac{s^{\prime}}{c^{\prime}}\left(1-2.0628 \frac{h^{\prime}}{c^{\prime}}\right)\right]}
\end{aligned}
$$

here, $Q_{\mathrm{LHV}}$ is the lower heating value of fuel, which is calculated by using Mendelyev's formula:

$$
Q_{\mathrm{LHV}}=33.91 c^{\prime}+125.6 h^{\prime}-10.89\left(o^{\prime}-s^{\prime}\right)-2.51\left(9 h^{\prime}-w^{\prime}\right)
$$

The quantities $h^{\prime}, c^{\prime}, o^{\prime}, s^{\prime}$ and $w^{\prime}$ in Equations $(32,33)$ represent the mass fractions of the elements carbon, hydrogen and oxygen, the sulfur and water contents in the fuel, respectively.

The last term on the right-hand side of Equation (31) illustrates exergy destruction in the cylinder due to combustion. It is calculated as:

$$
\dot{I}_{\text {comb }}=T_{0} \dot{S}_{\text {comb }}
$$

here, $\dot{S}_{\text {comb }}$ is the rate of entropy generation due to combustion irreversibilities. It is calculated from a two-zone combustion model of entropy balance as [27, 31]:

$$
\dot{S}_{\text {comb }}=\frac{d\left(m_{\mathrm{b}} s_{\mathrm{b}}\right)}{d \theta}+\frac{d\left(m_{\mathrm{u}} s_{\mathrm{u}}\right)}{d \theta}
$$


here, $m_{\mathrm{b}}$ and $m_{\mathrm{u}}$ are the burned and unburned masses of the cylinder contents, and $s_{\mathrm{b}}$ and $s_{\mathrm{u}}$ are the entropy values of the burned and unburned gases.

Additionally, exergy destruction due to heat transfer irreversibilities is defined as follows:

$$
\dot{I}_{\mathrm{Q}}=T_{0} \dot{S}_{\mathrm{Q}}
$$

Entropy production sourced from the heat transfer process is calculated as in Equation (37):

$$
\dot{S}_{\mathrm{Q}}=\frac{\dot{Q}_{\mathrm{b}}}{T_{\mathrm{b}}}+\frac{\dot{Q}_{\mathrm{u}}}{T_{\mathrm{u}}}
$$

here, $\dot{Q}_{\mathrm{b}}$ and $\dot{Q}_{\mathrm{u}}$ are the rates of heat loss from burned and unburned gas zones at temperatures $T_{\mathrm{b}}$ and $T_{\mathrm{u}}$, respectively.

Thus, the total irreversibilities can be calculated as:

$$
\dot{I}_{\text {tot }}=\dot{I}_{\text {comb }}+\dot{I}_{\mathrm{Q}}
$$

Various of the second law efficiencies (exergetic or availability efficiency, or effectiveness) are defined in the literature $[7,27,31]$. The following definition is used in this study:

$$
\eta_{\mathrm{II}}=\frac{\text { Exergy out }(\text { as work })}{\text { Exergy in }}=\frac{A_{\mathrm{W}}}{m_{\mathrm{f}} a_{\mathrm{f}, \mathrm{ch}}}
$$

Finally, the dead-state conditions were taken as $p_{0}=1 \mathrm{~atm}$ and $T_{0}=25^{\circ} \mathrm{C}$ for exergy analysis.

\section{NUMERICAL APPLICATIONS}

\subsection{Computer Program and Solution Procedure}

A computer code was written in Fortran to perform the numerical applications. Once the intake conditions are defined, the thermodynamic state of the cylinder charge can be predicted by solving the governing differential equations of the cycle model. The Dverk subroutine is used to integrate the differential equations. The composition and thermodynamic properties of the unburned and burned cylinder contents are computed by using the Fortran subroutines, FARG (Fuel-AirResidual Gas) and ECP (Equilibrium-Combustion-Products). Exergetic calculations are performed simultaneously, depending on the thermodynamic state of the cylinder contents. Finally, the results obtained can be corrected as follows [26]:

$$
\begin{gathered}
\varepsilon_{1}=1-v m / V \\
\varepsilon_{2}=1+W / \Delta(m u)+Q
\end{gathered}
$$

The validity of the computer program is fulfilled by fixing the values of $\varepsilon_{1}$ and $\varepsilon_{2}$ at the $10^{-4}$.

\subsection{Model Validity}

For the validation of the cycle model, the predictions from the model were compared with experimental data obtained
TABLE 1

Specifications of the engines

\begin{tabular}{l|c|c|c|c|c|c}
\hline Engines & $r_{c}(-)$ & $B(\mathrm{~mm})$ & $L_{s}(\mathrm{~mm})$ & $L_{\mathrm{cr}}(\mathrm{mm})$ & $Z(-)$ & $V_{\mathrm{d}}(\mathrm{L})$ \\
\hline Engine I [33] & 10 & 84.5 & 89 & 180 & 4 & 2 \\
\hline Engine II [34] & 10 & 80.6 & 88 & 176 & 4 & 1.8 \\
\hline Engine III [35] & 8 & 84 & 71.5 & 142 & 4 & 1.6 \\
\hline
\end{tabular}

from the literature [33-35] for the conditions specified in Figure 1 and the engine specifications given in Table 1. The predictions are generally in good agreement with the experimental data as seen in Figure 1. The deviations are about $0.2-9.1 \%$ for pressure in Figure 1a, $1.2-30.5 \%$ for the mass fraction burned in Figure 1b, 0-0.8\% for Brake Specific Fuel Consumption in Figure 1c, $0.9-5.4 \%$ for the second law (exergetic) efficiency in Figure 1d, 0-11.2\% for exergy loss with heat flow rate in Figure 1e and 11.9-19.8\% for exhaust exergy in Figure 1f. Thus, it can be said that the model has a sufficient level of confidence for parametric investigation.

\section{RESULTS AND DISCUSSION}

In this section, the differences between energy and exergy analysis are emphasized initially, and then the parametric exergy analysis is performed. Exergy analysis makes possible the identification of various exergy losses thanks to the friction, heat interaction and exhaust process and irreversibilities sourced from the fluid motions, mixture formation, heat transfer interaction and combustion phenomena, unlike an energy analysis, as mentioned in the Introduction. This situation can be clearly seen in Figure 2, which shows the results obtained from energy and exergy analysis for the specified conditions. As seen in Figure 2a and c, the irreversibilities can only be determined with the exergy analysis. Here, the irreversibilities arising from the heat interaction and combustion process are taken into consideration. In Figure $2 \mathrm{~b}$ and $\mathrm{d}$, there are also significant quantitative differences between the portions of the losses with heat interaction and exhaust and work output determined by means of energy and exergy analysis. The differences are about $3.81 \%$ for heat interaction, $2.85 \%$ for work interaction and $12.47 \%$ for exhaust losses. The sum of these differences is about $19.13 \%$, which corresponds to the irreversibilities computed from exergy analysis as seen in Figure 2d. The results show that the differences that cannot be ignored between energy and exergy analysis require the exergy analysis to improve the design and/or operation of the system by identifying the losses and irreversibilities in a realistic way. On the other hand, parametric exergy analysis was performed in this study for the engine specifications [33] given in Table 1. The variation of exergetic variables with engine speed is given in Figure 3a-f. Exergy transfer with heat $\left(A_{\mathrm{Q}}\right)$ decreases with increasing engine speed, as seen in Figure 3a. This variation can be 

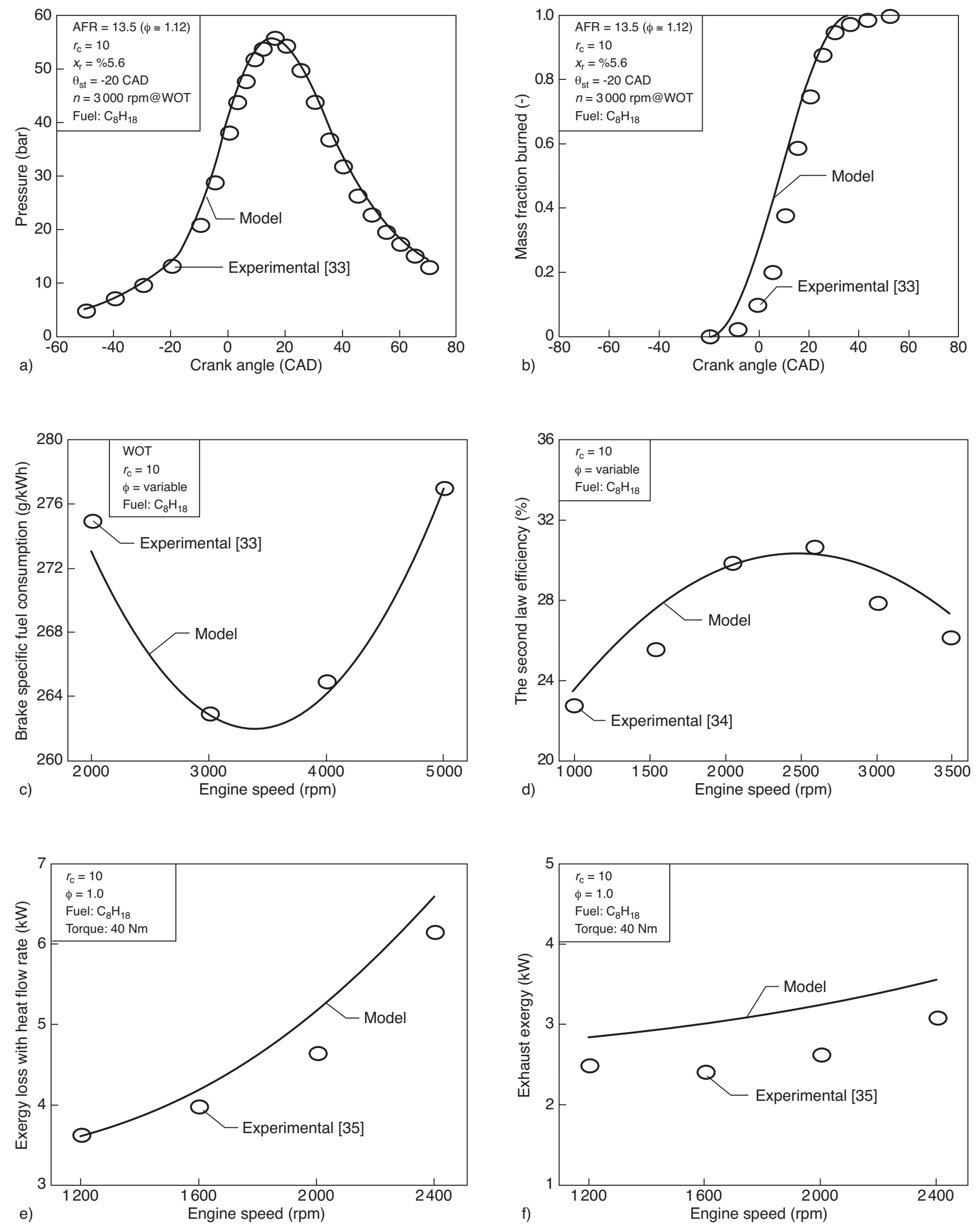

Figure 1

Comparison of various predicted and experimental data. 

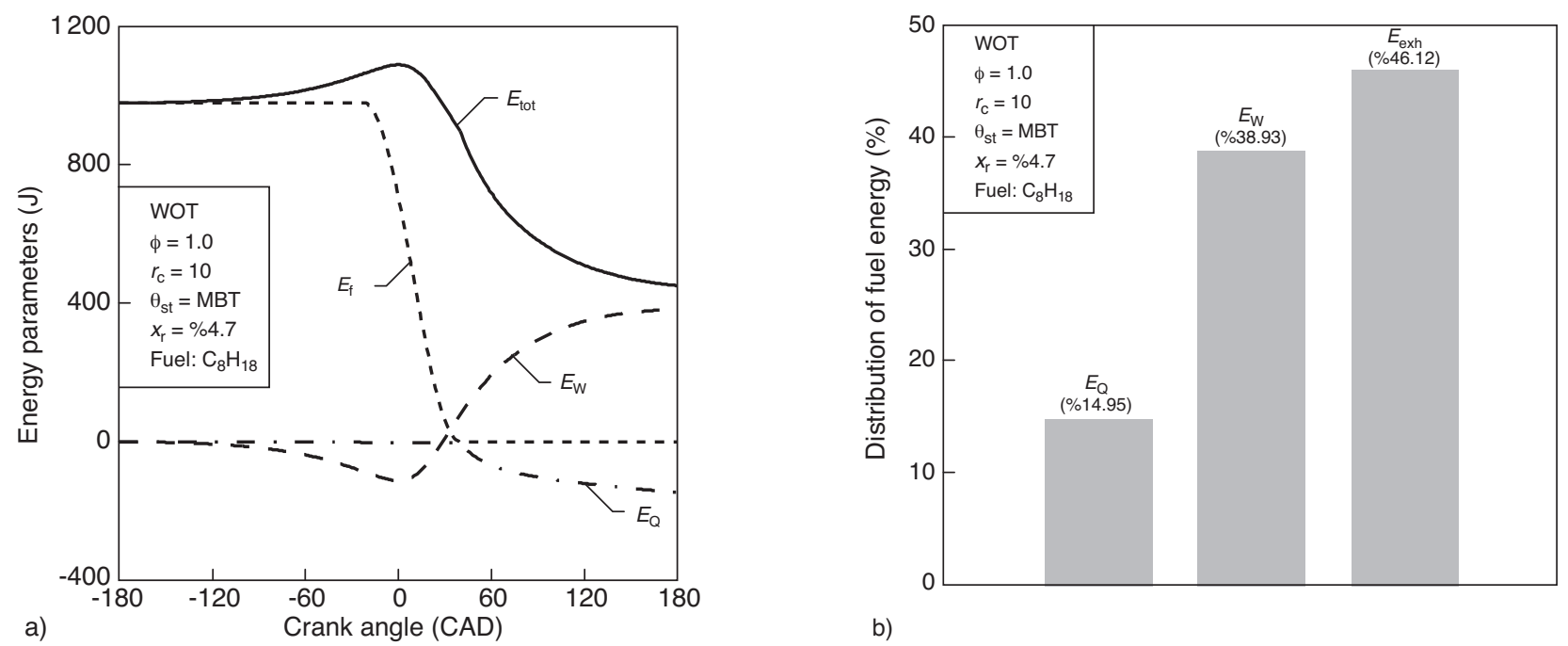

b)
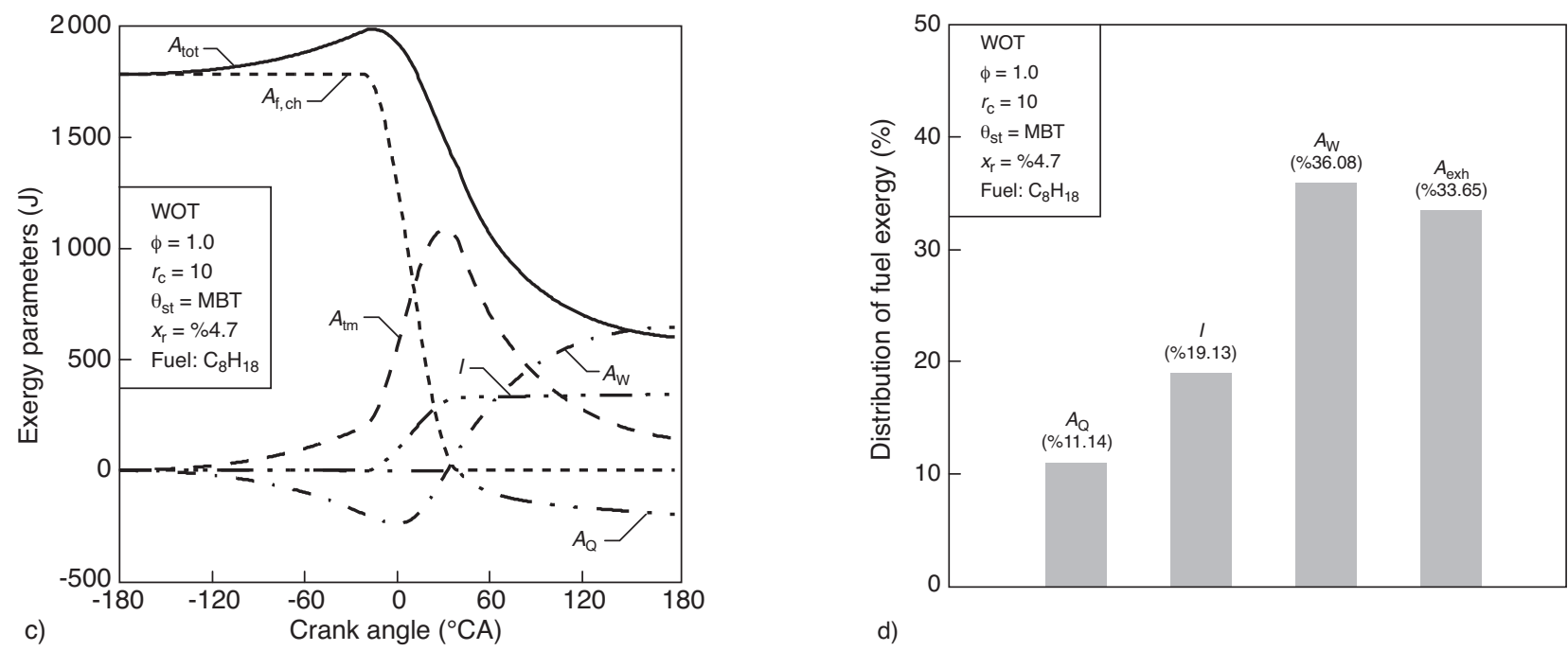

d)

Figure 2

Variation and distribution of energy and exergy parameters.

associated with the cycle duration. The amount of heat transfer to the cylinder wall and consequently $A_{\mathrm{Q}}$, is enhanced because of the expanded heat transfer (cycle) duration as the engine speed decreases. Therefore, the higher combustion temperatures occur, as seen in Table 2 because of the decreasing heat transfer since engine speed increases. The extended combustion duration given in Table 2 with increasing engine speed has an additional effect on these higher combustion temperatures. The values of $A_{\mathrm{Q}}$ for $3000 \mathrm{rpm}$ and $4500 \mathrm{rpm}$ are less in magnitude, about $44.9 \%$ and $68.4 \%$, than that of $1500 \mathrm{rpm}$. The physical meaning of these variations is that low engine speeds give the extra energy loss via increasing heat transfer, while high engine speeds generate the excessive heat loads on engine components because of the high temperatures.
Therefore, medium engine speeds can be evaluated as an ideal operating condition. Exergy transfer with work $\left(A_{\mathrm{W}}\right)$ in Figure $3 \mathrm{~b}$ has the maximum values for $3000 \mathrm{rpm}$ during expansion, while $4500 \mathrm{rpm}$ gives the highest values during compression because of the advanced spark timing. The negative values of $A_{\mathrm{W}}$ during compression illustrate that exergy is transferred to the cylinder content from the piston, which corresponds to the compression work. Conversely, exergy is transferred to the piston from the cylinder content during expansion and thus, useful work is obtained. The shortened combustion duration of the low engine speed as seen in Table 2 decreases the useful work by causing an early reduction in the pressure on the piston during expansion and the advanced spark timing of the high engine 

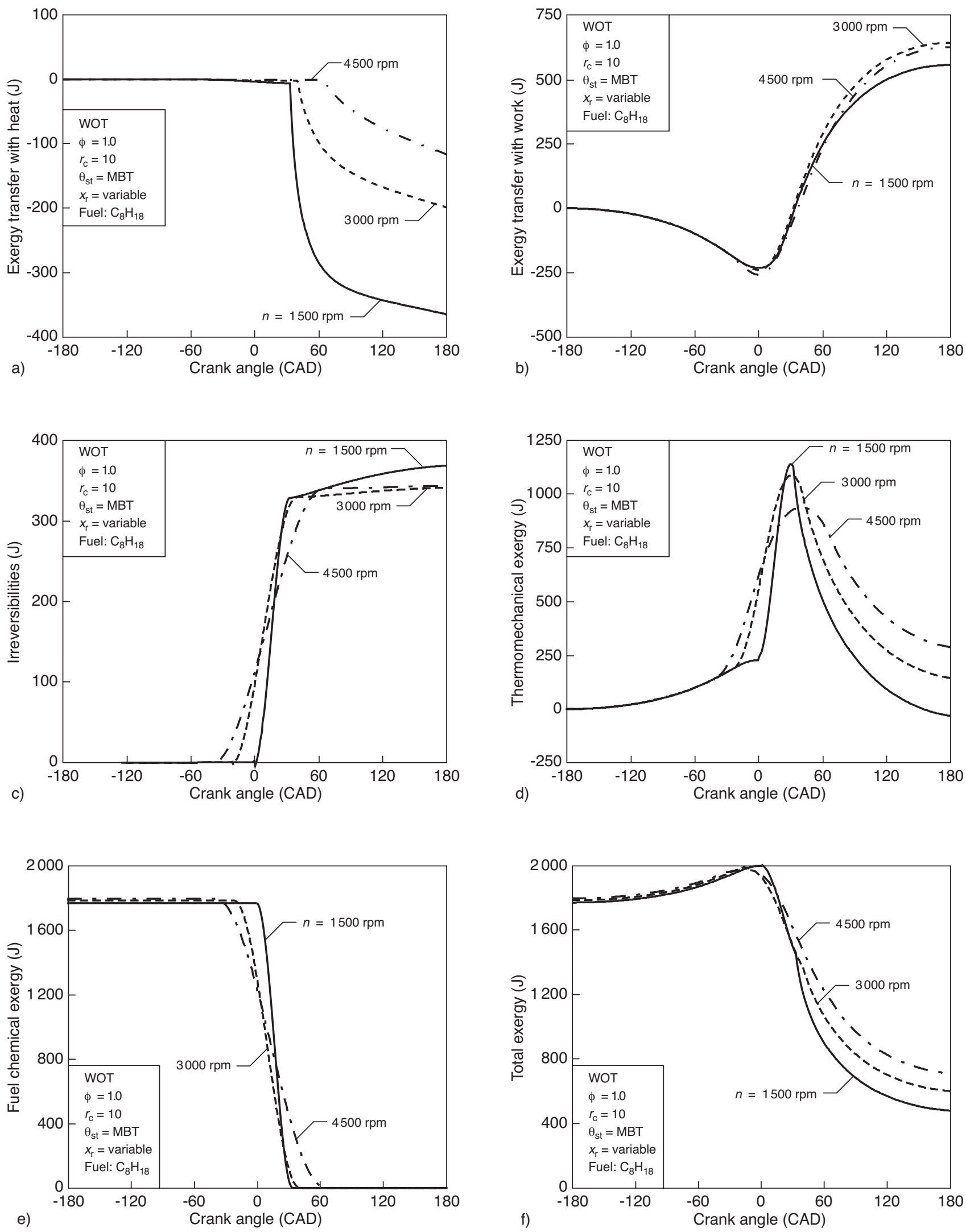

Figure 3

Variation of exergetic terms with engine speed. 
TABLE 2

The computed cycle and exergetic parameters

\begin{tabular}{|c|c|c|c|c|c|c|}
\hline Parameters & & $m_{\mathrm{f}}(\mathrm{g})$ & $A_{\mathrm{f}, \mathrm{ch}}(\mathrm{J})$ & $T_{\max }(\mathrm{K})$ & $B M E P$ (bar) & $\Delta \theta_{\mathrm{b}}(\mathrm{CAD})$ \\
\hline \multirow{3}{*}{$n(\mathrm{rpm}) @ \mathrm{WOT}$} & 1500 & $3.65 \times 10^{-2}$ & 1770 & 2634 & 10.1 & 36 \\
\hline & 3000 & $3.68 \times 10^{-2}$ & 1784 & 2711 & 11.4 & 62 \\
\hline & 4500 & $3.71 \times 10^{-2}$ & 1796 & 2743 & 10.6 & 105 \\
\hline \multirow{3}{*}{ BMEP (bar)@ 3000 rpm } & 4 & $1.65 \times 10^{-2}$ & 800 & 2609 & 4 & 62 \\
\hline & 7 & $2.50 \times 10^{-2}$ & 1212 & 2696 & 7 & 63 \\
\hline & 10 & $3.37 \times 10^{-2}$ & 1634 & 2761 & 10 & 64 \\
\hline
\end{tabular}

speed also creates more compression (negative) work that negatively affects the work output, while the medium engine speed gives the best useful work transfer. This variation can be related to the $B M E P$ values given in Table 2, because $B M E P$ is a main indicator of the work obtained during the cycle. The values of $A_{\mathrm{W}}$ for both 1500 and $4500 \mathrm{rpm}$ are less in magnitude, approximately $13.4 \%$ and $2.6 \%$, than that of $3000 \mathrm{rpm}$. Engine speed of $3000 \mathrm{rpm}$ also gives the minimum irreversibilities $(I)$ in Figure $3 \mathrm{c}$. The irreversibilities for the engine speed of $1500 \mathrm{rpm}$ increase because of the excessive heat transfer and, as cited in the literature [36], the low combustion temperature as given in Table 2 generates the increments in irreversibilities. On the other hand, the irreversibilities for $4500 \mathrm{rpm}$ are also relatively higher than $3000 \mathrm{rpm}$ because of the extended combustion duration as given in Table 2. Thus, the values of $I$ for 1500 and 4500 rpm are greater in magnitude, by about $8 \%$ and $0.6 \%$, than that of $3000 \mathrm{rpm}$. The variations in $A_{\mathrm{Q}}, A_{\mathrm{W}}$ and $I$ demonstrate that the engine speed of $3000 \mathrm{rpm}$ is the optimum speed among the tested engine speeds. Although the inducted fuel mass (or the supplied fuel exergy) is almost unchanged for all engine speeds, as seen in Table 2, the work output of the engine increases thanks to limited irreversibilities for an engine speed of $3000 \mathrm{rpm}$. Additionally, $3000 \mathrm{rpm}$ has reasonable exergy losses with heat interaction. These make $3000 \mathrm{rpm}$ the best performer in terms of exergy transfer with work output. The variation of thermomechanical exergy $\left(A_{\mathrm{tm}}\right)$ is presented in Figure $3 \mathrm{~d}$. The maximum value of $A_{\mathrm{tm}}$ increases and a narrower curve appears as engine speed decreases because of the shortened combustion duration, as seen in Table 2. The variations in $A_{\mathrm{tm}}$ are a combination of the variations in $A_{\mathrm{Q}}, A_{\mathrm{W}}$ and $I$. As seen in Figure $3 \mathrm{e}$, fuel chemical exergy $\left(A_{\mathrm{f}, \mathrm{ch}}\right)$ does not change significantly with varying engine speed at the start of compression, but the variation in combustion duration shifts the consumption of fuel exergy during combustion. The variations in total exergy $\left(A_{\text {tot }}\right)$ reflect the combination of $A_{\mathrm{tm}}$ and $A_{\mathrm{f}, \mathrm{ch}}$ in Figure $3 \mathrm{f}$. The exhaust exergy $\left(A_{\text {exh }}\right)$ that determines the remaining exergy in the cylinder at the end of expansion in Figure $3 \mathrm{f}$ increases with increasing engine speed in consequence of expanded combustion duration, which causes higher exhaust temperature and pressure. Thus, more exergy is swept with hotter exhaust gases as engine speed increases. The values of $A_{\mathrm{exh}}$ are greater in magnitude, by approximately 25.3 and $48 \%$ for 3000 and $4500 \mathrm{rpm}$, compared with that of $1500 \mathrm{rpm}$.

Figure 4a-f shows the variation of exergetic variables with engine load. Brake Mean Effective Pressure (BMEP) is selected to symbolize the engine load, which is varied by adjusting the intake manifold pressure. $A_{\mathrm{Q}}$ increases with increasing engine load thanks to increasing inducted fuel mass (that means more fuel energy or exergy input), which supplies higher combustion temperatures, as tabulated in Table 2. Therefore, the values of $A_{\mathrm{Q}}$ are higher in magnitude, by about $69.7 \%$ for $B M E P$ of 7 bar and $169.2 \%$ for $B M E P$ of $10 \mathrm{bar}$, in comparison with $B M E P$ of 4 bar. As seen in Figure $4 \mathrm{~b}$, exergy transfer with work increases with increasing engine load because of the higher $B M E P$ values, which are the result of the higher cylinder pressures sourced from the higher fuel energy input, as cited before. Additionally, more compression work is needed as the engine load is increased, as seen in Figure $4 \mathrm{~b}$. The increments in $A_{\mathrm{W}}$ in magnitude are approximately $58.4 \%$ for $B M E P$ of 7 bar and $121.9 \%$ for $B M E P$ of 10 bar compared with $B M E P$ of 4 bar. Irreversibilities also increase with increasing engine load in Figure $4 \mathrm{c}$. The variation in $I$ can be attributed to the composition and amount of inducted cylinder charge and combustion products, as cited in the literature. It was declared that the absolute value of the destroyed availability during combustion increases as the inducted fuel mass and combustion-generated products increases [36]. The increments in $I$ in magnitude are about $46.1 \%$ for $B M E P$ of 7 bar and $97.9 \%$ for $B M E P$ of 10 bar compared with $B M E P$ of 4 bar. In Figure $4 \mathrm{~d}, A_{\mathrm{tm}}$ increases with the increasing engine load as a result of variations in exergy transfers with heat and work and also irreversibilities. The variation in $A_{\mathrm{f}, \mathrm{ch}}$ is given in Figure 4e; it significantly increases with the increasing engine load. The increment in $A_{\mathrm{f}, \mathrm{ch}}$ is sourced from more inducted fuel mass to meet the increasing engine load, as given in Table 2, and also the reduction in the residual gas fraction. $A_{\text {tot }}$ increases naturally with increasing engine load in Figure $4 \mathrm{f}$ because the variation in $A_{\mathrm{tot}}$ reflects the combined variations in $A_{\mathrm{tm}}$ and $A_{\mathrm{f}, \mathrm{ch}} \cdot A_{\mathrm{f}, \mathrm{ch}}$ is dominated during compression, while $A_{\mathrm{tm}}$ is dominated during expansion. In Figure 4f, $A_{\text {exh }}$, that corresponds 

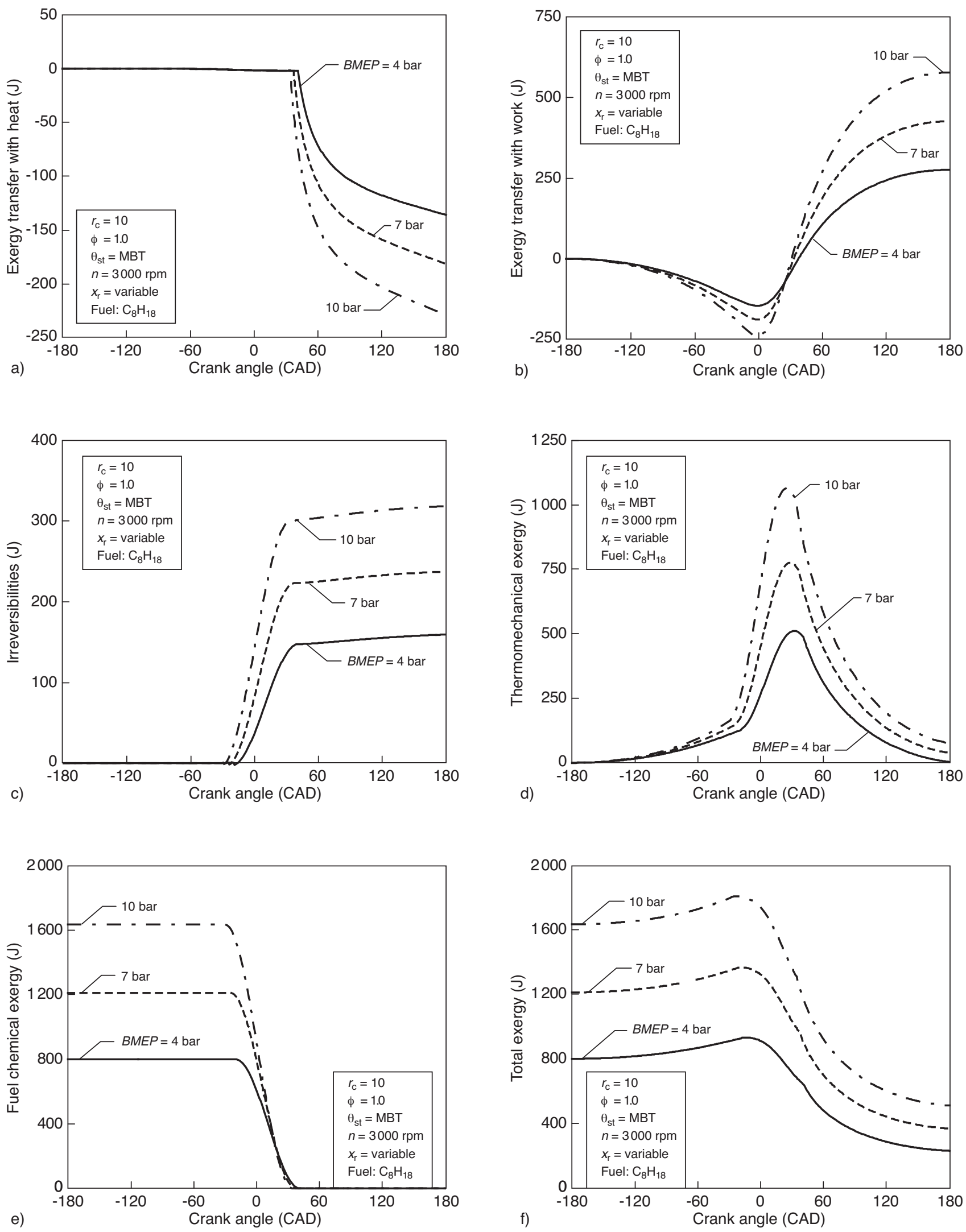

Figure 4

Variation of exergetic terms with engine load. 

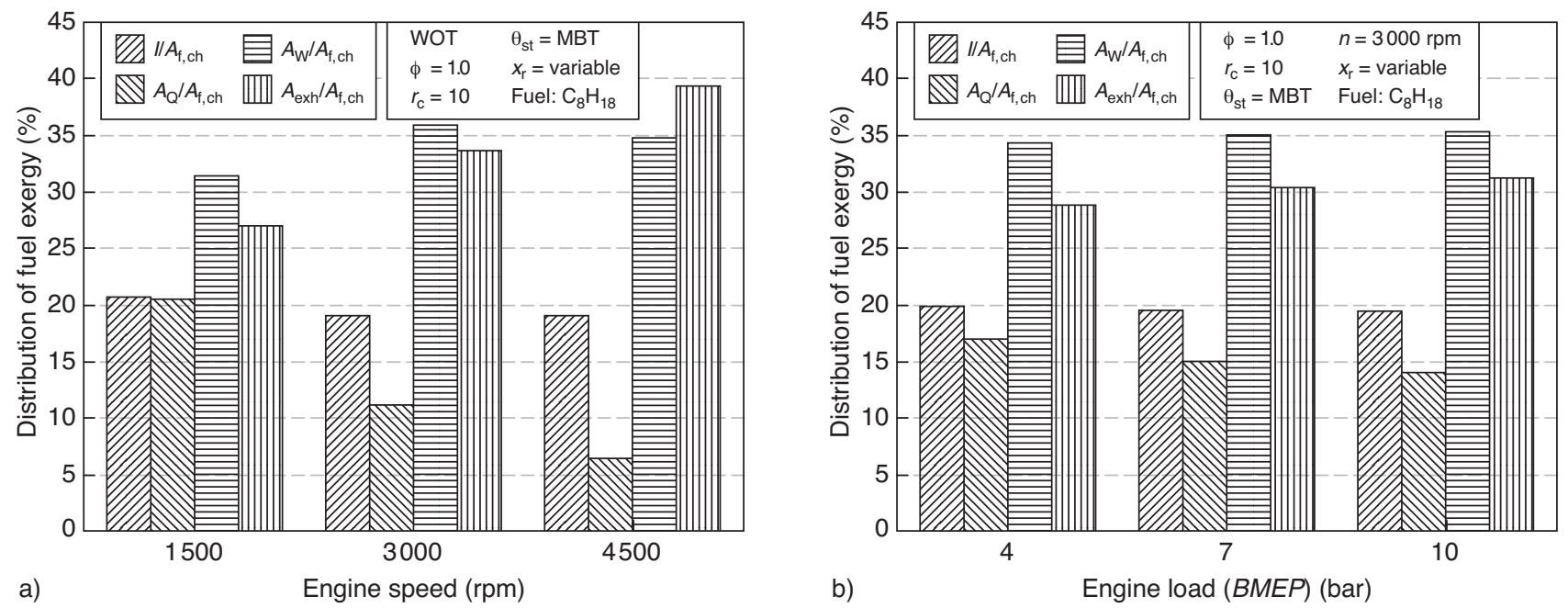

Figure 5

Distribution of fuel exergy for various engine speeds and loads.

to the remaining exergy in the cylinder at the end of the expansion period, also increases with increasing engine load because of more supplied fuel energy to the cylinder, which creates higher cylinder temperatures and pressures. The increments in $A_{\text {exh }}$ in magnitude are about $59.6 \%$ for $B M E P$ of 7 bar and $136.1 \%$ for $B M E P$ of 10 bar when compared with $B M E P$ of 4 bar.

The distribution of the exergetic variables, i.e. $I, A_{\mathrm{Q}}, A_{\mathrm{W}}$, $A_{\text {exh }}$, into the fuel exergy (or the normalization of exergetic variables by fuel chemical exergy) for various engine speeds is given in Figure 5a. These data are obtained from the cycle integrated exergy values corresponding to the calculations presented in Figure 3, so generally parallel variations appear in Figure 3 due to the fuel chemical exergy that is almost stable with the varying engine speed. The percentage of $I$ for $3000 \mathrm{rpm}$ is lower by about 1.7 than $1500 \mathrm{rpm}$ and higher by about 0.01 than $4500 \mathrm{rpm}$ because of the small increase in $A_{\mathrm{f}, \mathrm{ch}}$ for $4500 \mathrm{rpm}$, as seen in Figure 3e, while its magnitude is lower for $3000 \mathrm{rpm}$. The percentage of $A_{\mathrm{Q}}$ for $1500 \mathrm{rpm}$ is higher by about 9.5 than $3000 \mathrm{rpm}$ and by 14.1 than $4500 \mathrm{rpm}$. The percentage of $A_{\mathrm{W}}$ for $3000 \mathrm{rpm}$ is higher by about 4.5 than $1500 \mathrm{rpm}$ and by 1.1 than $4500 \mathrm{rpm}$. The percentage of $A_{\text {exh }}$ for $4500 \mathrm{rpm}$ is higher by about 6.7 than $3000 \mathrm{rpm}$ and by 12.4 than $1500 \mathrm{rpm}$. It can be concluded that the engine speed of $3000 \mathrm{rpm}$ is the optimal speed on the basis of earlier statements related to Figure 3 and the distribution of exergetic variables in Figure 5a due to the fact that it has the ratio of the highest $A_{\mathrm{W}}$ and acceptable portions of irreversibilities and exergy losses sourced from heat transfer and the exhaust. The distribution of exergetic variables, i.e. $I, A_{\mathrm{Q}}, A_{\mathrm{W}}, A_{\mathrm{exh}}$, into the fuel exergy (or the normalization of exergetic variables by fuel chemical exergy) for various engine loads is given in Figure 5b. These data are obtained from the cycle integrated exergy values corresponding to the calculations presented in Figure 4, but the variations of some exergetic parameters such as $I$ and $A_{\mathrm{Q}}$ are different from the cycle integrated exergy values because of increases in $A_{\mathrm{f}, \mathrm{ch}}$, as seen in Figure 4e. The percentage of $I$ for $B M E P$ of 4 bar is higher by about 0.3 than $B M E P$ of 7 bar and by 0.4 than $B M E P$ of 10 bar. The percentage of $A_{\mathrm{Q}}$ for $B M E P$ of 4 bar is higher by about 2.0 than $B M E P$ of 7 bar and by 3.0 than $B M E P$ of $10 \mathrm{bar}$. The percentage of $A_{\mathrm{W}}$ for $B M E P$ of 4 bar is lower by about 0.7 than $B M E P$ of 7 bar and by 0.9 than $B M E P$ of $10 \mathrm{bar}$. The percentage of $A_{\text {exh }}$ for $B M E P$ of $4 \mathrm{bar}$ is lower by about 1.6 than $B M E P$ of 7 bar and by 2.4 than $B M E P$ of 10 bar. It can be concluded that the engine load of 10 bar (high load) is an optimal load in the light of previous statements related to Figure 4 and the distribution of exergetic variables in Figure $5 \mathrm{~b}$ due to the fact that it has the ratio of the highest $A_{\mathrm{W}}$ and the lowest portions of irreversibilities and exergy losses except for $A_{\text {exh }}$.

The variation of the first law efficiency $\left(\eta_{\mathrm{I}}\right)$, the second law efficiency $\left(\eta_{\text {II }}\right)$ and Brake Specific Fuel Consumption $(B S F C)$ for various engine speeds and loads is given in Table 3. $\eta_{\mathrm{I}}$ and $\eta_{\mathrm{II}}$ are the maximum and BSFC is the minimum for $3000 \mathrm{rpm}$, as seen in Table 3. As cited above, the main reason for the best performance of $3000 \mathrm{rpm}$ is that the work output of the engine increases thanks to limited irreversibilities. The less irreversible (or improved) combustion process is also obtained thanks to the increased volumetric efficiency, as given in Table 3 . Thus, the engine speed of $3000 \mathrm{rpm}$ gives the best first and second law efficiencies. The second law efficiency also serves as a more realistic evaluation than the first law, because the second law efficiency values for all 
TABLE 3

The performance parameters

\begin{tabular}{c|c|c|c|c|c}
\hline Parameters & & $\eta_{\mathrm{vol}}(\%)$ & $\eta_{\mathrm{I}}(\%)$ & $\eta_{\mathrm{II}}(\%)$ & $B S F C(\mathrm{~g} / \mathrm{kWh})$ \\
\hline \multirow{3}{*}{$n(\mathrm{rpm}) @$ WOT } & 1500 & 86.3 & 33.9 & 31.5 & 242.4 \\
\cline { 2 - 6 } & 3000 & 91.6 & 38.9 & 36.1 & 228.1 \\
\cline { 2 - 6 } & 4500 & 88.7 & 37.7 & 34.9 & 258.6 \\
\hline \multirow{3}{*}{$\begin{array}{c}\text { BMEP (bar) @ } \\
\text { 3000 rpm }\end{array}$} & 4 & 41.6 & 37.1 & 34.3 & 293.6 \\
\cline { 2 - 6 } & 10 & 62.5 & 37.8 & 35.1 & 252.1 \\
\cline { 2 - 6 } & & 83.9 & 38.1 & 35.3 & 236.8 \\
\hline
\end{tabular}

engine speeds are lower than those of the first law due to the fact that the chemical exergy of the fuel is higher than its calorific value, as seen in Equations $(32,33)$. On the other hand, Brake Specific Fuel Consumption is the least for $3000 \mathrm{rpm}$ thanks to the almost stable absolute mass of inducted fuel. The variation in $\eta_{\mathrm{I}}, \eta_{\mathrm{II}}$ and $B S F C$ with respect to the engine load are shown in Table $3 . \eta_{\mathrm{I}}$ and $\eta_{\mathrm{II}}$ are the maximum and $B S F C$ is the minimum for $B M E P$ of 10 bar (high load), as seen in Table 3. The engine work output increases with the increasing engine load due to the increasing inducted fuel mass (which supplies more energy input), as tabulated in Table 2, and the increased volumetric efficiency (which improves the combustion process), as given in Table 3. The decrements in the portion of the irreversibilities and exergy losses except for exhaust exergy thanks to improved combustion make an additional contribution to the first and second law efficiencies and fuel consumption. Thus, the engine load of 10 bar gives the best performance in terms of $\eta_{\mathrm{I}}, \eta_{\mathrm{II}}$ and $B S F C$.

\section{CONCLUSIONS}

In this study, the effects of some operating parameters such as engine speed and load in Spark Ignition engines are investigated via exergy analysis by using a thermodynamic cycle model. The following conclusions can be drawn from the results of the study:

- exergy transfer with heat decreases, while exergy transfer with exhaust gases increases with the increasing engine speed. Fuel chemical exergy stays almost stable with varying engine speed. A medium engine speed, i.e. $3000 \mathrm{rpm}$, gives the maximum exergy output as work and the minimum irreversibilities. The engine speed of $3000 \mathrm{rpm}$ also gives the best first and second law efficiencies besides the minimum Brake Specific Fuel Consumption. Thus, it can be concluded that medium engine speeds serve both efficient and economical operation in view of exergy analysis;

- exergy transfers with heat, work and exhaust and also irreversibilities increase with the increasing engine load. The fuel chemical exergy also increases as engine load increases. On the other hand, the percentages of irreversibilities and exergy transfer with heat into the fuel exergy decrease, while the percentage of exergy transfers with work and exhaust increase with increasing engine load. The first and second law efficiencies are the maximum and the Brake Specific Fuel Consumption is the minimum for the high engine load. Thus, it can be concluded that high engine loads serve both efficient and economical operation in view of exergy analysis;

- additionally, it must be noted that engine operation under high engine speeds or high engine load has a wearing and life-consuming effect on engine components because of the friction and thermal load.

\section{REFERENCES}

1 Heywood J.B. (1988) Internal Combustion Engine Fundamentals, McGraw Hill, New York.

2 Bayraktar H., Durgun O. (2003) Mathematical Modeling of Spark-Ignition Engine Cycles, Energy Sources 25, 651-666.

3 Erduranlı P., Koca A., Sekmen Y. (2005) Performance Calculation of a Spark Ignition Engine According to the Ideal Air-Fuel Cycle Analysis, Gazi University J. Sci. 18, 1, 103-114.

4 Chow A., Wyszynski M.L. (1999) Thermodynamic Modelling of Complete Engine Systems-A Review, Proc. IMechE Part D: J. Automobile Engineering 213, 403-415.

5 Andreassi L., Cordiner S., Rocco V. (2003) Modeling the Early Stage of Spark Ignition Engine Combustion Using the KIVA-3V Code Incorporating an Ignition Model, Int. J. Engine Res. 4, 3, 179-192.

6 Caton J.A. (2002) Illustration of the Use of an Instructional Version of a Thermodynamic Cycle Simulation for a Commercial Automotive Spark-Ignition Engine, Int. J. Mech. Eng. Educ. 30, 4, 283-297.

7 Rakopoulos C.D., Giakoumis E.G. (2006) Second-Law Analyses Applied to Internal Combustion Engines Operation, Progr. Energ. Combust. Sci. 32, 2-47.

8 Rakopoulos C.D., Giakoumis E.G. (2005) The Influence of Cylinder Wall Temperature Profile on the Second-Law Diesel Engine Transient Response, Appl. Therm. Eng. 25, 1779-1795.

9 Moran M.J., Shapiro H.N. (2000) Fundamentals of Engineering Thermodynamics, John Wiley \& Sons, New York.

10 Cengel Y.A., Boles M.A. (1994) Thermodynamics, An Engineering Approach, McGraw Hill, New York.

11 Bejan A. (2002) Fundamentals of Exergy Analysis, Entropy Generation Minimization, and the Generation of Flow Architecture, Int. J. Energy Res. 26, 545-565.

12 Szargut J. (2005) Exergy Analysis, Research in Progress Thermodynamics 3, 7, 31-3.

13 Traupel W. (1957) Reciprocating Engine and Turbine in Internal Combustion Engineering, Proceedings of the International Congress of Combustion Engines (CIMAC), Zurich, Switzerland.

14 Patterson D.J. (1962) A Comprehensive Cycle Analysis and Digital Computer Simulation for Spark-Ignited Engines, $P h D$ Thesis, Michigan University.

15 Primus R.J., Hoag K.L., Flynn P.F., Brands M.C. (1984) An Appraisal of Advanced Engine Concepts Using Second Law Techniques, SAE Technical Papers 841287, 73-87. 
16 Alkidas A.C. (1988) The Application of Availability and Energy Balances to a Diesel Engine, J. Eng. Gas Turbine. Power 110, 462-469.

17 Lior N., Rudy G.J. (1988) Second-Law Analysis of an Ideal Otto Cycle, Energy Convers. Manage. 28, 4, 327-334.

18 Shapiro H.N., Van Gerpen J.H. (1989) Two Zone Combustion Models for Second Law Analysis of Internal Combustion Engines, SAE Technical Papers 890823, 1408-1422.

19 Kumar S.V. (1989) Exergy as a Second Law Analysis Parameter in Diesel Engine Cycle Simulation, PhD Thesis, University of Illinois.

20 Gallo W.L.R., Milanez L.F. (1992) Exergetic Analysis of Ethanol and Gasoline Fueled Engines, SAE Technical Papers 920809, 907-915.

21 Rakopoulos C.D. (1993) Evaluation of a Spark Ignition Engine Cycle Using First and Second Law Analysis Techniques, Energy Convers. Manage. 34, 12, 1299-1314.

22 Alasfour F.N. (1997) Butanol-A Single-Cylinder Engine Study: Availability Analysis, Appl. Therm. Eng. 17, 6, 537-549.

23 Caton J.A. (2000) Operation Characteristics of a Spark-Ignition Engine Using the Second Law of Thermodynamics: Effects of Speed and Load, SAE World Congress, Detroit, MI.

24 Kopac M., Kokturk L. (2005) Determination of Optimum Speed of an Internal Combustion Engine by Exergy Analysis, Int. J. Exergy 2, 1, 40-54.

25 Sayin C., Hosoz M., Canakci M., Kilicaslan I. (2006) Energy and Exergy Analyses of a Gasoline Engine, Int. J. Energy Res. 31, 3, 259-273.

26 Ferguson C.R. (1985) Internal Combustion Engine Applied Thermosciences, John Wiley \& Sons, New York.

27 Sezer I. (2008) Application of Exergy Analysis to Spark Ignition Engine Cycle, PhD Thesis, Karadeniz Technical University.
28 Ferguson C.R., Green R.M., Lucht R.P. (1987) Unburned Gas Temperatures in Internal Combustion Engine II: Heat Release Computations, Combust. Sci. Technol. 55, 63-81.

29 Bayraktar H., Durgun O. (2004) Development of an Empirical Correlation for Combustion Durations in Spark Ignition Engines, Energy Convers. Manage. 45, 1419-1431.

30 Van Gerpen J.H., Shapiro H.N. (1990) Second Law Analysis of Diesel Engine Combustion, J. Eng. Gas Turbine. Power 112, 129-37.

31 Zhang S. (2002) The Second Law Analysis of a Spark Ignition Engine Fueled with Compressed Natural Gas, MS Thesis, University of Windsor.

32 Kotas T.J. (1995) The Exergy Method of Thermal Plant Analysis, Krieger Publishing, Malabar.

33 Chen C., Veshagh A. (1992) A Refinement of Flame Propagation Combustion Model for Spark-Ignition Engines, SAE Technical Papers 920679, 1-22.

34 Kahraman N., Ceper B., Akansu S.O., Aydin K. (2009) Investigation of Combustion Characteristics and Emissions in a Spark-Ignition Engine Fuelled with Natural Gas-Hydrogen Blends, Int. J. Hydrogen Energy 34, 1026-1034.

35 Sayin C., Hosoz M., Canakci M., Kilicaslan I. (2007) Energy and Exergy Analyses of a Gasoline Engine, Int. J. Energy Res. 31, 259-273.

36 Caton J.A. (2000) On the Destruction of Availability due to Combustion Processes - with Specific Application to InternalCombustion Engines, Energy 25, 1097-1117.

Final manuscript received in January 2012 Published online in August 2012 